\title{
Human adenovirus Coinfection aggravates the severity of Mycoplasma pneumoniae pneumonia in children
}

\author{
Jiaojiao Gao, Lili Xu, Baoping Xu, Zhengde Xie and Kunling Shen ${ }^{*}$
}

\begin{abstract}
Background: Mycoplasma pneumoniae (M. pneumoniae) is an important pathogen of community-acquired pneumonia (CAP) in children. The coinfection rate of M. pneumoniae pneumonia (MPP) can reach 52\% in some areas, but the effects of coinfection with different pathogens have not been clearly recognized.

Methods: The cases of MPP hospitalized in Beijing Children's Hospital from 1/1/2014 to 12/31/2016 were screened. MPP patients coinfected with Human adenovirus (HAdV) were categorized into the research group. Patients with single M. pneumoniae infection were categorized into the control group, matching the research group by age and admission time with a ratio of 1:3. Clinical manifestations, laboratory examinations, and disease severity were compared between these two groups.
\end{abstract}

Results: A total of 2540 hospitalized MPP cases were screened in Beijing Children's Hospital, among which thirty cases were enrolled in the research group and ninety cases were enrolled in the control group. The results indicated that patients in the research group had longer hospital stays, longer fever durations and a higher rate of dyspnea, as well as a larger proportion applications of oxygen therapy and noninvasive continuous positive airway pressure (NCPAP). No obvious differences were found in lab examinations within the two groups. Regarding disease severity, the proportions of extremely severe pneumonia and severe disease defined by the clinical score system were higher in the research group than in the control group.

Conclusion: Compared with single M. pneumoniae infection, MPP coinfected with HAdV in children was relatively more serious.

Keywords: Mycoplasma pneumoniae, Adenovirus, Pneumonia, Case-control study, Children

\footnotetext{
* Correspondence: xiezhengde@bch.com.cn; kunlingshen1717@163.com National Clinical Research Center for Respiratory Diseases, Key Laboratory of Major Diseases in Children, Ministry of Education, Beijing Key Laboratory of Pediatric Respiratory Infection diseases, Research Unit of Critical Infection in Children, Chinese Academy of Medical Sciences, 2019RU016, Laboratory of Infection and Virology, Beijing Pediatric Research Institute, Beijing Children's Hospital, Capital Medical University, National Center for Children's Health, Beijing, China
}

(c) The Author(s). 2020 Open Access This article is licensed under a Creative Commons Attribution 4.0 International License, which permits use, sharing, adaptation, distribution and reproduction in any medium or format, as long as you give appropriate credit to the original author(s) and the source, provide a link to the Creative Commons licence, and indicate if changes were made. The images or other third party material in this article are included in the article's Creative Commons licence, unless indicated otherwise in a credit line to the material. If material is not included in the article's Creative Commons licence and your intended use is not permitted by statutory regulation or exceeds the permitted use, you will need to obtain permission directly from the copyright holder. To view a copy of this licence, visit http://creativecommons.org/licenses/by/4.0/ The Creative Commons Public Domain Dedication waiver (http://creativecommons.org/publicdomain/zero/1.0/) applies to the data made available in this article, unless otherwise stated in a credit line to the data. 


\section{Background}

Mycoplasma pneumoniae (M. pneumoniae) is an important pathogen of community-acquired pneumonia (CAP) in hospitalized children. $M$. pneumoniae circulates throughout a year, and there is an epidemic of MP every 3-7 years [1]. During the epidemic, M. pneumoniae is responsible for $20-40 \%$ of community-acquired bacterial pneumonia [2]. A study of respiratory pathogens in children with lower respiratory tract infections from Shanghai showed that $M$. pneumoniae was the most common pathogen from 2013 to 2015 [3]. In addition, the detection rate of $M$. pneumoniae in pediatric CAP had a positive correlation with the increase in the age of the children [4].

M. pneumoniae infection can be self-limited [5], but it can also lead to severe pneumonia $[6,7]$ and even acute respiratory distress syndrome (ARDS) in children. $M$. pneumoniae infection can also cause many extrapulmonary manifestations [8,9], which makes diagnosis and treatment more difficult. In addition, M. pneumoniae can damage the epithelial cells and cilia of the human airway, affect the function of the mucus-ciliary clearance system, and affect host immune function. The coinfection rate can reach $52 \%$ in Mycoplasma pneumoniae pneumonia (MPP) [10], but the effects of coinfection with other pathogens on the clinical features of MPP have not been clearly recognized.

Human adenovirus (HAdV) is an important pathogen of respiratory tract infection in children and is responsible for $4-10 \%$ of pediatric CAP [11]. To elucidate the impact of HAdV coinfection on the clinical manifestation of MPP in children, we performed this casecontrol study.

\section{Methods}

\section{Study population}

The cases of MPP hospitalized in Beijing Children's Hospital from $1 / 1 / 2014$ to $12 / 31 / 2016$ were screened. MPP patients coinfected with HAdV were categorized into the research group. For each patient in the research group, we matched three cases with single $M$. pneumoniae infection as controls. The control group was matched to the research group by age and admission period, suggesting that every child in the control groups should be in the same age group as the patient in the research group, and these patients were collected within 2 weeks before and 2 weeks after the coinfection cases. The nearest cases were recruited first. In detail, the patients were divided into four age groups: < 2 years old, $2-5$ years old, $5-10$ years old, and $>10$ years old.

\section{Inclusion and exclusion criteria}

The inclusion criteria for the research group were as follows: 1) clinical manifestations of pneumonia, such as fever, cough and radiographic findings of pneumonia; 2) evidence of $M$. pneumoniae infection: serological $M$. pneumoniae antibody titer $\geq 1: 160$ or a positive result of M. pneumoniae RNA of oropharyngeal swabs with realtime polymerase chain reaction (PCR); and 3) evidence of HAdV infection: a positive result of HAdV-DNA from blood or respiratory samples or a positive result of HAdV antigen from nasopharyngeal aspirates.

Control subjects should meet the first and second inclusion criteria of the research group and have a negative result after HAdV examination.

Children with any of the following factors were excluded: 1) neonatal pneumonia; 2) coinfected with other pathogens confirmed by laboratory tests; 3) convalescent pneumonia; 4) long-term use of glucocorticoids or immunosuppressive agents; and 5) congenital heart or chronic lung disease.

If a patient in the research group received recurrent fever after more than 3 days of normal temperature and HAdV infection was confirmed at the same time, then he or she was diagnosed with nosocomial infection.

\section{Clinical information collection}

The clinical manifestations, laboratory examinations, imaging characteristics, and disease severity were compared between these two groups. Three methods were used to evaluate the severity of disease. 1) According to the national guidelines for pediatric CAP in China, pneumonia was divided into mild and severe (Table 1). 2) According to the same guidelines, extremely severe pneumonia was diagnosed if the child presented with central cyanosis, severe respiratory distress, refusal to eat, dehydration or altered consciousness (somnolence, coma, convulsions), and he or she experienced extremely severe pneumonia. 3) Based on the clinical scoring system designed by Carmen L. Larranaga and other scholars to classify the severity of acute lower respiratory tract infection caused by respiratory syncytial virus, we divided pneumonia into mild, moderate and severe grades (Table 2) [12].

The extrapulmonary manifestations involved in our study included mucocutaneous manifestations, myocardial damage and liver damage. Myocardial damage includes abnormal Electrocardiogram (ECG) and Creatine kinase isoenzyme (CK-MB) above the upper limit of normal $(25 \mathrm{U} / \mathrm{L})$. Liver damage refers to glutamic-pyruvic transaminase (ALT) above the upper limit of normal (40 U/L).

\section{Statistical analysis}

Statistical analysis was performed with SPSS Statistics (v21, IBM Corp., USA). The independent sample t-test and two independent sample rank sum test were used to compare continuous variables between two groups. Pearson's chi-square or Fisher's exact test was used for 
Table 1 Disease Severity Assessment of CAP in Children

\begin{tabular}{lll}
\hline Clinical manifestations & Mild CAP & Severe CAP \\
\hline General situation & Good & Not good \\
Refusal to eat or dehydration & No & Yes \\
Disorder of consciousness & No & Yes \\
Respiratory rate & Normal or slightly increase & Significantly increase ${ }^{a}$ \\
Cyanosis & No & Yes \\
Dyspnea & No & Yes \\
Multilobar infiltrates & No & Yes \\
Pleural effusion & No & Yes \\
Oxygen saturation & $>0.96$ & $\leq 0.92$ \\
Extrapulmonary manifestations & No & Yes \\
Assessment & Present all above manifestations & Present any of the above manifestations \\
\hline
\end{tabular}

${ }^{a}$ Significantly increased respiratory rate: infants $>70 \mathrm{bpm}$, older children $>50 \mathrm{bpm}$

categorical data. $P \leq 0.05$ was considered to be statistically significant.

\section{Results}

\section{Patients enrollment}

From 2014 to 2016, 2540 hospitalized MPP cases were found in Beijing Children's Hospital, and 53 cases were diagnosed with HAdV coinfection. However, 11 of these cases were excluded: 4 cases had insufficient lab examinations, 5 cases had coinfection with other pathogens, 1 case had convalescent pneumonia, and 1 case had congenital heart disease. Among the remaining 42 coinfection cases, 12 cases could not be included because no matching cases were found. Eventually, 30 cases were included in the research group, and 90 cases were included in the control group.

\section{Demographic characteristics of the patients}

Of the 30 research cases, 2 cases were $<2$ years old, 14 cases were 2-5 years old, 11 cases and 3 cases were 510 years old and $>10$ years old, respectively. Most of these patients visited our hospital in autumn and winter.

Boys accounted for $67 \%$ in the research group and $50 \%$ in the control group (Table 3 ).

\section{Comparisons of clinical characteristics}

The clinical characteristics of the two groups are shown in Table 3. The research group had a longer hospital stay (10 days vs 8 days, $P=0.001$ ), longer fever duration (14 days vs 9 days, $P<0.01)$, increased heart rate $(116$ bpm vs $110 \mathrm{bpm}, P=0.043)$ and a higher rate of dyspnea (23.3\% vs $2.2 \%, P=0.001)$.

\section{Comparisons of laboratory and radiographic findings}

No difference was found in laboratory examination and radiographic findings between the two groups, and the proportion of extrapulmonary manifestations was similar between the two groups (Table 4).

Although the platelet count was higher in the research group, the data in both groups were within the normal reference range for children.

\section{Comparisons of treatment}

For treatment, more than half of the children in both groups received fiberoptic bronchoscopy, compared with $53.3 \%$ in the research group and $65.6 \%$ in the control group, and the difference was not statistically significant (Table 5).

No patients were treated with invasive mechanical ventilation or transferred to the PICU. However, our study showed that the proportion of oxygen therapy

Table 2 Clinical Scoring System

\begin{tabular}{|c|c|c|c|c|c|}
\hline \multirow[t]{2}{*}{ Factor } & \multicolumn{4}{|c|}{ Score } & \multirow{2}{*}{$\begin{array}{l}\text { Maximal } \\
\text { Score }^{c}\end{array}$} \\
\hline & 0 & 1 & 2 & 3 & \\
\hline Hospitalization & No & $\leq 5 \mathrm{~d}$ & $>5 d$ & $\mathrm{PICU}^{\mathrm{a}}(+1 / 2)$ & $0-5$ \\
\hline Supplemental oxygen & No & $\leq 1 \mathrm{~d}$ & $1-3 d(+1)$ & $>3 d(+1)$ & $0-4$ \\
\hline Max $\mathrm{FiO}_{2}(\%)$ & 21 & $22-30$ & $\geq 31$ & $M V^{b}(+2)$ & $0-5$ \\
\hline
\end{tabular}

${ }^{a}$ PICU Pediatric intensive care unit

${ }^{\mathrm{b}} M V$ Mechanical ventilation

${ }^{\mathrm{C}} \mathrm{A}$ total score value of 7 or greater was defined as severe disease, and less than 7 were considered as mild or moderate disease. 
Table 3 Clinical Characteristics between the Research Group and the Control Group

\begin{tabular}{llll}
\hline Characteristic & Control group $(\boldsymbol{n}=90)$ & Research group $(\boldsymbol{n}=30)$ & $\boldsymbol{P}$ value \\
\hline Males $\mathbf{n}(\%)$ & $45(50 \%)$ & $20(67 \%)$ & 0.084 \\
Hospital stay (day), median & $8(3-15)$ & $10(3-33)$ & 0.001 \\
Fever days before admission, median & $7(2-46)$ & $7.5(3-25)$ & 0.751 \\
Fever duration (day), median & $9(2-31)$ & $14(7-28)$ & $<0.01$ \\
Max temperature ( $\left.{ }^{\circ} \mathbf{C}\right)$, median & $39.50(37.8-41.0)$ & $39.55(38.0-40.5)$ & 0.474 \\
Heart rate $(\mathbf{b p m})$, mean & $110(80-142)$ & $116(88-155)$ & $24(20-56)$ \\
Respiratory rate $(\mathbf{b p m})$, median & $24(18-44)$ & $1(3.3 \%)$ & - \\
Disturbance of consciousness, $\mathbf{n}$ & 0 & 0 & - \\
Cyanosis, $\mathbf{n}$ & 1 & $7(23.3 \%)$ & 0.25 \\
Dyspnea, $\mathbf{n}$ & $2(2.2 \%)$ & $19(63.3 \%)$ & 0.001 \\
Abnormal breath sounds, $\mathbf{n}$ & $55(61.1 \%)$ & 0.503 \\
\hline
\end{tabular}

(93\% vs $64 \%, P=0.001$ ) and noninvasive continuous positive airway pressure (NCPAP) $(16.7 \%$ vs $0, P=0.01)$ was higher in the research group than in the control group (Table 5).

The readmission rate was $10 \%$ in both groups. Three patients in the research group and eight in the control group were readmitted for fiberoptic bronchoscopy, and one patient in the control group returned to the hospital because of bronchiolitis obliterans.

\section{Comparisons of the disease severity}

In terms of disease severity, the proportions of severe

CAP in the research group and the control group were
87 and $80 \%$, respectively, and the difference was not statistically significant. However, the proportion of extremely severe pneumonia in the research group (23.3\%) was higher than that in the control group $(3.3 \%)(P=$ 0.002). According to the clinical scoring system, the severe proportions in the research group and the control group were 46.6 and $14.4 \% \quad(P=0.001)$, respectively (Table 5).

Nosocomial infection and nonnosocomial infection cases Further analysis of nosocomial infection was performed according to the time of diagnosis of HAdV infection.

Table 4 Laboratory and Radiographic Findings between the Research Group and the Control Group

\begin{tabular}{|c|c|c|c|}
\hline Characteristics & Control group $(\boldsymbol{n}=90)$ & Research group $(\boldsymbol{n}=30)$ & $\boldsymbol{P}$ value \\
\hline Leukocyte count $\left(\times 10^{\wedge} 9 / \mathrm{L}\right)$, median & $7.355(2.9-20.4)$ & $6.995(3.8-20.9)$ & 0.833 \\
\hline Neutrophil (\%), mean & $58.8 \pm 12.9(26.4-86.2)$ & $59.4 \pm 12.1(31.0-86.0)$ & 0.805 \\
\hline Lymphocyte (\%), mean & $30.8 \pm 12.1(8.9-64.9)$ & $31.1 \pm 10.7(9.9-56.4)$ & 0.880 \\
\hline Anemia, $\mathrm{n}$ & $14(15.6 \%)$ & $7(23.3 \%)$ & 0.239 \\
\hline Platelet $\left(\times 10^{\wedge} 9 / \mathrm{L}\right)$, median & $305(90-680)$ & $264(111-644)$ & 0.01 \\
\hline C-reactive protein $>8 \mathrm{mg} / \mathrm{L}, \mathrm{n}$ & $51(56.7 \%)$ & $16(53.3 \%)$ & 0.456 \\
\hline Elevated serum CK-MB, $\mathbf{n}$ & $2(2.2 \%)$ & $2(6.7 \%)$ & 0.263 \\
\hline Abnormal ECG, $n^{a}$ & $36(46.7 \%)$ & $10(45.5 \%)$ & 0.555 \\
\hline Decrease $\mathrm{PaO}_{2}, \mathrm{n}^{\mathrm{b}}$ & 0 & 0 & - \\
\hline LDH (U/L), median & $322(172-1820)$ & $348(190-693)$ & 0.337 \\
\hline Elevated serum PCT, $n$ & $43(47.8 \%)$ & $18(60 \%)$ & 0.407 \\
\hline Multilobar infiltrates, $\mathrm{n}$ & $61(67.8 \%)$ & $21(70 \%)$ & 0.506 \\
\hline Pleural effusion, $n$ & $23(25.6 \%)$ & $8(26.7 \%)$ & 0.54 \\
\hline Rash, $\mathrm{n}$ & $6(6.7 \%)$ & $1(3.3 \%)$ & 0.44 \\
\hline Myocardial damage, $n$ & $37(41.1 \%)$ & $11(36.7 \%)$ & 0.418 \\
\hline Liver damage, $\mathrm{n}$ & $12(13.3 \%)$ & $1(3.3 \%)$ & 0.112 \\
\hline
\end{tabular}

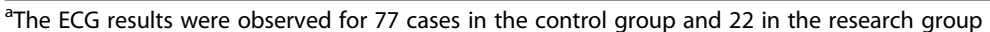

${ }^{b}$ The results of the arterial blood gas analysis were found for 51 cases in the control group and 23 cases in the research group 
Table 5 Treatment and Disease Severity between the Research Group and Control Group

\begin{tabular}{llll}
\hline Characteristic, $\mathrm{n}(\%)$ & Control group $(\boldsymbol{n}=90)$ & Research group $(\boldsymbol{n}=30)$ & $\mathrm{P}$ value \\
\hline Fiberoptic bronchoscopy & $59(65.6 \%)$ & $16(53.3 \%)$ & 0.278 \\
Oxygen therapy & $58(64 \%)$ & $28(93 \%)$ & 0.001 \\
NCPAP & 0 & $5(16.7 \%)$ & 0.01 \\
Invasive mechanical ventilation & 0 & 0 & - \\
PICU admission & 0 & $3(10 \%)$ & - \\
Readmission & $9(10 \%)$ & $26(87 \%)$ & 0.301 \\
Severe CAP & $72(80 \%)$ & $7(23.3 \%)$ & 0.002 \\
Extremely severe pneumonia & $3(3.3 \%)$ & $14(46.6 \%)$ & 0.001 \\
Severe disease defined by clinical score system & $13(14.4 \%)$ &
\end{tabular}

Nine children in the research group were nosocomial infection cases. Comparing these 9 children with their neighbors, the difference was consistent with the total research group and the control group (Table 6).

The remaining 21 co-infected children in the research group were admitted to the hospital with adenovirus coinfection. When compared with their neighbors, no significant differences were found in hospital stay, NCPAP use and the proportion of extremely severe pneumonia between the two groups (Table 7).

\section{Discussion}

Compared with M. pneumoniae mono-infection, patients coinfected with HAdV had a longer hospital stay and fever duration and a higher rate of dyspnea, which led to a higher rate of oxygen therapy and NCPAP use, as well as a higher proportion of extremely severe pneumonia and severe disease defined by the clinical score system.

There was no similar study on the effect of coinfection with HAdV in MPP, but there are some studies on MPP coinfections with other pathogens.
In terms of clinical manifestations, our study showed that the duration of fever was longer in the research group, regardless of the nosocomial infection status. Chen and colleagues studied 201 children with MPP in China, of which 103 children were coinfected with other pathogens, including Chlamydia, viruses and bacteria, and 6 of these children were coinfected with HadV. The results showed that the proportion of fever duration > 10 days $(40.8 \%)$ in the mixed infection group was significantly higher than that in the nonmixed infection group $(24.5 \%, P=0.014)$, which was consistent with our results [13]. It is reasonable that coinfection with HAdV can prolong the clearance time of the pathogen and aggravate the host immune response, which leads to longer inflammation times. However, when Chin-Yung Chiu et al. compared the clinical manifestations of $M$. pneumoniae mono-infection $(n=31), M$. pneumoniae with Streptococcus pneumoniae coinfection $(n=9)$ and $M$. pneumoniae with virus coinfection $(n=19)$, these authors found that the fever duration of M. pneumoniaeand Streptococcus pneumoniae-infected children was

Table 6 Comparisons of Nosocomial Infection Cases in the Research Group and Their Matched Controls

\begin{tabular}{llll}
\hline Characteristics & Control group $(\boldsymbol{n}=27)$ & Research group $(\boldsymbol{n}=9)$ & P value \\
\hline Hospital stay (day), median & $7(3-13)$ & $19(9-33)$ & $7(5-12)$ \\
Fever days before admission, median & $7(2-40)$ & $19(12-28)$ & - \\
Fever duration (day), median & $8(2-31)$ & $39.18 \pm 0.62$ & 0.001 \\
Max temperature $\left({ }^{\circ} \mathbf{C}\right)$, mean & $39.32 \pm 0.67$ & 0 & 0.571 \\
Cyanosis, $\mathbf{n}(\%)$ & 0 & $3(33.3 \%)$ & - \\
Dyspnea, $\mathbf{n}(\%)$ & $1(3.7 \%)$ & $7(77.8 \%)$ & $9(100 \%)$ \\
Fiberoptic bronchoscopy & $20(74.1 \%)$ & $3(33.3 \%)$ & 0.041 \\
Oxygen therapy & $16(59.3 \%)$ & $1(11.1 \%)$ & 0.602 \\
NCPAP & 0 & $9(100 \%)$ & 0.022 \\
Readmission & $3(11.1 \%)$ & $3(33.3 \%)$ & 0.012 \\
Severe CAP & $23(85.2 \%)$ & $5(55.6 \%)$ & 0.745 \\
Extremely severe pneumonia & $0 \%$ & $5(18.5 \%)$ & 0.298 \\
Severe disease defined by clinical score system & & 0.012 \\
\hline
\end{tabular}


Table 7 Comparisons of Nonnosocomial Infection Cases in the Research Group and Their Matched Controls

\begin{tabular}{|c|c|c|c|}
\hline Characteristics & Control group $(\boldsymbol{n}=63)$ & Research group $(\boldsymbol{n}=21)$ & $P$ value \\
\hline Hospital stay (day), median & $8.0(3-15)$ & $9.0(3-12)$ & 0.069 \\
\hline Fever days before admission, median & $7(0-46)$ & $9(3-21)$ & 0.449 \\
\hline Fever duration (day), median & $9(2-29)$ & $12(7-26)$ & 0.028 \\
\hline Max temperature $\left({ }^{\circ} \mathrm{C}\right)$, median & $39.5(37.8-41.0)$ & $39.8(38.0-40.5)$ & 0.255 \\
\hline Heart rate $(\mathrm{bpm})$, mean & $112 \pm 13(80-142)$ & $117 \pm 14(88-148)$ & 0.134 \\
\hline Respiratory rate (bpm), median & $25(18-44)$ & $25(21-56)$ & - \\
\hline Disturbance of consciousness, $n$ & 0 & $1(4.8 \%)$ & 0.25 \\
\hline Cyanosis, $\mathrm{n}$ & $1(1.6 \%)$ & 0 & 0.75 \\
\hline Dyspnea, $\mathrm{n}$ & $1(1.6 \%)$ & $4(19 \%)$ & 0.013 \\
\hline Abnormal breath sounds, $n$ & $39(61.9 \%)$ & $14(66.7 \%)$ & 0.797 \\
\hline Leukocyte count $\left(\times 10^{\wedge} 9 / L\right)$, median & $7.49(2.9-20.42)$ & $5.95(3.78-13.88)$ & 0.614 \\
\hline Anemia, $n$ & $11(17.5 \%)$ & $6(28.6 \%)$ & 0.213 \\
\hline Platelet $\left(\times 10^{\wedge 9 / L}\right)$, mean & $323 \pm 117(90-622)$ & $238 \pm 70(111-342)$ & $<0.001$ \\
\hline C-reactive protein $>8 \mathrm{mg} / \mathrm{L}, \mathrm{n}$ & $34(54.0 \%)$ & $12(57.1 \%)$ & 0.502 \\
\hline Elevated serum CK-MB, $n$ & $2(3.2 \%)$ & $2(9.5 \%)$ & 0.264 \\
\hline Multilobar infiltrates, $n$ & $42(66.7 \%)$ & $13(61.9 \%)$ & 0.442 \\
\hline Pleural effusion, $n$ & $17.0(27 \%)$ & 7 (33.3\%) & 0.383 \\
\hline Rash, $\mathrm{n}$ & $4(4.3 \%)$ & 0 & 0.309 \\
\hline Myocardial damage, $n$ & $22(34.9 \%)$ & $6(28.6 \%)$ & 0.4 \\
\hline Liver damage, $\mathrm{n}$ & $9(14.3 \%)$ & $1(4.8 \%)$ & 0.226 \\
\hline Fiberoptic bronchoscopy & 39 (61.9\%) & $9(42.9 \%)$ & 0.102 \\
\hline Oxygen therapy & $38(60.3 \%)$ & 19 (90.5\%) & 0.008 \\
\hline NCPAP & 0 & $2(9.5 \%)$ & 0.06 \\
\hline Readmission & $6(9.5 \%)$ & $2(9.5 \%)$ & 0.683 \\
\hline Severe CAP & 49 (77.8\%) & $17(81.0 \%)$ & 0.512 \\
\hline Extremely severe pneumonia & $3(4.8 \%)$ & $4(19 \%)$ & 0.062 \\
\hline Severe disease defined by clinical score system & $8(12.7 \%)$ & $9(42.9 \%)$ & 0.005 \\
\hline
\end{tabular}

longer than that of M. pneumoniae mono-infected children, but there was no significant difference between $M$. pneumoniae mono-infection and virus coinfection [14]. In this study, only 7 children were coinfected with HAdV in a total of 19 virus-coinfection patients. The different types of the pathogens involved in this study may be the reason for the disparate findings. As our study only focused on HAdV coinfection, it may better reflect the effects of HAdV infection on the clinical manifestations of MPP. Furthermore, our study reduced the effects of confounding factors, such as age and admission time by matching.

We also found that the incidence of dyspnea in the research group was higher than that in the control group. Therefore, the proportions of oxygen therapy and NCPAP were higher in the research group. In 2015, Jiang et al. conducted a study on the clinical characteristics of 593 hospitalized CAP patients with pathogens confirmed in the Children's Hospital of Soochow
University. The proportions of oxygen therapy among the single bacteria group and mixed bacteria and viruses group were 2.7 and $9.5 \%$, respectively $(P=0.02)$. These results suggested that the proportion of oxygen therapy was higher in the mixed group than in the single bacteria group. However, there was no further analysis of the specific pathogen of the mixed infections [15].

The incidence of dyspnea in HAdV-induced lower respiratory tract infection was as high as $40.7 \%$ [16]. An analysis of 213 children with severe HAdV pneumonia by Liu et al. showed that the incidence of respiratory failure was $82.2 \%$, and 70 cases required mechanical ventilation [17]. Moreover, cases of severe pneumonia caused by HAdV requiring extracorporeal membrane oxygenation (ECMO) have been reported in Taiwan and abroad $[18,19]$. In our study, none of these cases required invasive mechanical ventilation, which may be associated with early and timely oxygen therapy and NCPAP use. In combination with the results of our 
study and former studies, we suggest that physicians should pay attention to the possibility of HAdV coinfection in the treatment of MPP when dyspnea appears. If necessary, timely isolation can prevent nosocomial infection.

Regarding the severity of disease, we found that the proportion of extremely severe pneumonia and severe disease defined by the clinical score system was higher in the research group. The different results of different comparison methods are related to the different parameters involved. Lu et al. studied refractory $M$. pneumoniae pneumonia (RMPP) in children and found that the proportion of severe pneumonia in the coinfection group was higher than that in the mono-infection group (7.35\% vs $0.46 \%, P=0.003$ ) [20]. Huong Ple T conducted a study on the risk factors of severe atypical pneumonia. By multivariate logistic regression analysis, coinfection with respiratory virus was found to be one of the risk factors for severe atypical CAP in children $(\mathrm{OR}=4.36$, 95\% CI $=1.46-13.0, P=0.008)$ [21], which was consistent with our findings. Interactions of pathogens contribute to aggression of the disease severity, and the specific mechanism still needs further study.

The analysis of nosocomial infections showed that the proportion of extremely severe pneumonia in the 9 nosocomial infection cases was higher than that in their matched cases, and this difference was not observed in nonnosocomial infections. These results suggested that the proportion of extremely severe pneumonia increased significantly when nosocomial HAdV infections occurred.

From November 1996 to January 1997, 13 cases of nosocomial HAdV type 7 infection were reported in a pediatric ward of a Japanese hospital. The source of infection was a 2-year-old boy with HAdV pneumonia, pleural effusions and meningitis. Thirteen children who had been in contact with this patient in the ward developed HAdV pneumonia, and all but one patient required oxygen inhalation because of hypoxemia, and two of these patients were ventilated with a respirator. Notably, 5 of the 13 patients were hospitalized with MPP before nosocomial infection [22]. Although researchers had not assessed the severity of pneumonia, the dependence of the children on oxygen therapy could still indicate the severity of the disease in children with nosocomial infections.

We believe that the infection of HAdV acquired in the hospital is equivalent to a "secondary strike", which may aggravate the host immune response and increase the severity of the MPP. Hence, we suggest that pediatricians isolate HAdV-infected children, and the strict handwashing of medical staff is recommended to avoid serious complications of nosocomial infection in children with MPP.

This study still has some shortcomings. First, as a retrospective study, missing data is inevitable; for example, ECG results and arterial blood gas analysis data were not available in some children. Second, the number of cases was relatively small. A larger sample, multicenter, prospective study is needed.

\section{Conclusions}

Compared with single $M$. pneumoniae infection, MPP coinfection with HAdV in children has a longer duration of fever, longer hospital stay, higher proportion of dyspnea, higher proportion of oxygen therapy and more severe disease status defined by the clinical score system.

\section{Abbreviations}

M. pneumoniae: Mycoplasma pneumoniae; CAP: Community-acquired pneumonia; ARDS: Acute respiratory distress syndrome; MPP: Mycoplasma pneumoniae pneumonia; HAdV: Human adenovirus; PCR: Real-time polymerase chain reaction; NCPAP: Noninvasive continuous positive airway pressure; PICU: Pediatric intensive care unit; CRP: C-reactive protein; PCT: Calcitonin; ALT: Glutamic-pyruvic transaminase; CK-MB: Creatine kinase isoenzyme; ECG: Electrocardiogram; IQR: Interquartile range; 95\% Cl: 95\% confidence interval; ECMO: Extracorporeal membrane oxygenation; RMPP: Refractory Mycoplasma pneumoniae pneumonia

\section{Acknowledgments}

Not applicable.

\section{Authors' contributions}

JJG acquired clinical data, made contributions to the analysis and interpretation of data, and drafted the manuscript with the help of LLX and BPX. ZDX and KLS conceived and designed the study. All authors read and approved the final version of the manuscript and agree to be accountable for all aspects of the work.

\section{Funding}

This work was supported by grants from the National Major S \& T Research Projects for the Control and Prevention of Major Infectious Diseases in China (2017ZX10103004-004, 2018ZX10003006-001-004, 2018ZX10305409-001004). The funders had no role in study design, data collection and analysis, decision to publish, or preparation of the manuscript.

\section{Availability of data and materials}

The datasets used and/or analysed during the current study are available from the corresponding author on reasonable request.

\section{Ethics approval and consent to participate}

This study was performed in strict accordance with the human subject protection guidance of Ministry of Science and Technology of China, and the study protocol was approved by the Ethical Review Committee of Beijing Children's Hospital with judgment's reference number 2015-47. Written consent was obtained from the parents or guardians of all participants before data collection

\section{Consent for publication}

Not applicable.

\section{Competing interests}

The authors have no potential conflicts of interest.

Received: 28 October 2019 Accepted: 11 June 2020

Published online: 16 June 2020

\section{References}

1. Jacobs E, Ehrhardt I, Dumke R. New insights in the outbreak pattern of mycoplasma pneumoniae. Int J Med Microbiol. 2015;305(7):705-8.

2. Waites KB, Xiao L, Liu Y, Balish MF, Atkinson TP. Mycoplasma pneumoniae from the respiratory tract and beyond. Clin Microbiol Rev. 2017;30(3):747-809. 
3. Liu P, Xu M, He L, Su L, Wang A, Fu P, Lu L, Wang C, Xu J. Epidemiology of respiratory pathogens in children with lower respiratory tract infections in Shanghai, China, from 2013 to 2015. Jpn J Infect Dis. 2018;71(1):39-44.

4. Jain S, Williams DJ, Arnold SR, Ampofo K, Bramley AM, Reed C, Stockmann C, Anderson EJ, Grijalva CG, Self WH, et al. Community-acquired pneumonia requiring hospitalization among U.S. children. N Engl J Med. 2015;372(9): 835-45.

5. Yan $Y$, Wei $Y$, Jiang $W$, Hao C. The clinical characteristics of corticosteroidresistant refractory mycoplasma Pneumoniae pneumonia in children. Sci Rep. 2016;6:39929.

6. Izumikawa K. Clinical features of severe or fatal mycoplasma pneumoniae pneumonia. Front Microbiol. 2016;7:800.

7. Miyashita N, Obase Y, Ouchi K, Kawasaki K, Kawai Y, Kobashi Y, Oka M. Clinical features of severe mycoplasma pneumoniae pneumonia in adults admitted to an intensive care unit. J Med Microbiol. 2007:56(Pt 12):1625-9.

8. Meyer Sauteur PM, Unger WW, Nadal D, Berger C, Vink C, van Rossum AM Infection with and carriage of mycoplasma pneumoniae in children. Front Microbiol. 2016;7:329.

9. Olson D, Watkins LK, Demirjian A, Lin X, Robinson CC, Pretty K, Benitez AJ, Winchell JM, Diaz MH, Miller LA, et al. Outbreak of mycoplasma pneumoniae-associated Stevens-Johnson syndrome. Pediatrics. 2015;136(2): e386-94.

10. Michelow IC, Olsen K, Lozano J, Rollins NK, Duffy LB, Ziegler T, Kauppila J, Leinonen M, McCracken GH Jr. Epidemiology and clinical characteristics of community-acquired pneumonia in hospitalized children. Pediatrics. 2004; 113(4):701-7.

11. JD C. Adenoviruses. In: Textbook of pediatric infectious diseases. edn. Edited by Feigin R. Philadelphia: WB Saunders; 1998. p. 1666-84.

12. Larranaga CL, Ampuero SL, Luchsinger VF, Carrion FA, Aguilar NV, Morales PR, Palomino MA, Tapia LF, Avendano LF. Impaired immune response in severe human lower tract respiratory infection by respiratory syncytial virus. Pediatr Infect Dis J. 2009;28(10):867-73.

13. Chen LL, Cheng YG, Chen ZM, Li SX, Li XJ, Wang YS. Mixed infections in children with mycoplasma pneumoniae pneumonia. Zhonghua Er Ke Za Zhi. 2012;50(3):211-5.

14. Chiu CY, Chen CJ, Wong KS, Tsai MH, Chiu CH, Huang YC. Impact of bacterial and viral coinfection on mycoplasmal pneumonia in childhood communityacquired pneumonia. J Microbiol Immunol Infect. 2015;48(1):51-6.

15. Jiang W, Wu M, Zhou J, Wang Y, Hao C, Ji W, Zhang X, Gu W, Shao X. Etiologic spectrum and occurrence of coinfections in children hospitalized with community-acquired pneumonia. BMC Infect Dis. 2017;17(1):787.

16. Liu C, Xiao Y, Zhang J, Ren L, Li J, Xie Z, Xu B, Yang Y, Qian S, Wang J, et al. Adenovirus infection in children with acute lower respiratory tract infections in Beijing, China, 2007 to 2012. BMC Infect Dis. 2015;15:408

17. Liu ALHY, Yang Y, Shu C, Dai JH, Li QB. Clinical features of 213 cases of severe adenovirus pneumonia in children. J Clin Pediatr. 2013;8:726-9.

18. Hung KH, Lin LH. Adenovirus pneumonia complicated with acute respiratory distress syndrome: a case report. Medicine (Baltimore). 2015; 94(20):e776.

19. Hage E, Huzly D, Ganzenmueller T, Beck R, Schulz TF, Heim A. A human adenovirus species B subtype 21a associated with severe pneumonia. J Inf Secur. 2014;69(5):490-9.

20. Lu YH, ZXX YYD, Gu WJ, Chen ZR, Zhu CH, Wang YQ, Huang L, Shao XJ, Ji $W$. Role and influence of coinfection factor to refractory mycoplasma pneumoniae pneumonia in children. J Clin Pediatr. 2017;35(2):81-5.

21. Huong Ple T, Hien PT, Lan NT, Binh TQ, Tuan DM, Anh DD. First report on prevalence and risk factors of severe atypical pneumonia in Vietnamese children aged 1-15 years. BMC Public Health. 2014;14:1304.

22. Wesley AG, Pather M, Tait D. Nosocomial adenovirus infection in a paediatric respiratory unit. J Hosp Infect. 1993;25(3):183-90.

\section{Publisher's Note}

Springer Nature remains neutral with regard to jurisdictional claims in published maps and institutional affiliations.

Ready to submit your research? Choose BMC and benefit from:

- fast, convenient online submission

- thorough peer review by experienced researchers in your field

- rapid publication on acceptance

- support for research data, including large and complex data types

- gold Open Access which fosters wider collaboration and increased citations

- maximum visibility for your research: over $100 \mathrm{M}$ website views per year

At BMC, research is always in progress.

Learn more biomedcentral.com/submissions 